УДК 004.231.3

[0000-0002-0426-7891] О. Б. Півень, к.ф.--м.н., професор,

e-mail: pivolegbor@gmail.com

О. В. Бойко, магістрант

e-mail: boyko7894@gmail.com

Черкаський державний технологічний університет

б-р Шевченка, 460, м. Черкаси, 18006, Україна

\title{
МІКРОКОНТРОЛЕРНА СИСТЕМА КЕРУВАННЯ ПОЛИВОМ ЗЕМЕЛЬНИХ ДІЛЯНОК ІЗ ОБМІНОМ ДАНИХ
}

Запропоновано мікроконтролерну систему під керуванням мобільного додатка для операційної системи Android, яка дає змогу здійснювати моніторинг та керування системою поливу земельних ділянок. Розроблено автономну систему поливу багатьох ділянок землі під керуванням багатьох мікроконтролерних систем на базі NodeMCU. Розроблена система автоматизованого поливу не потребує значних капіталовкладень $i$ має оптимальне співвідношення ціна/якість, зручна в користуванні і має технічні можливості для збільшення кількості земельних ділянок для автоматизованого поливу. До складу автоматизованої системи поливу входять: сонячні панелі, частотний перетворювач, насос, ємність для води, електронний клапан для води, мікроконтролерна система і агрегати для поливу. Мікроконтролерна система складається з таких компонентів: плата з мікроконтролером, датчики температури повітря та вологості трунту, годинник реального часу, датчики верхнього та нижнього рівня води, реле керування роботою водяного насоса та електромагнітним клапаном для води. Для зв'язку між мікроконтролерною системою та користувачем використовується спеціальний протокол MQTT. Для управління поливною системою та ї̈ моніторингу використовується мобільний додаток MQTT Dashboard, розроблений для операщійної системи Android. 3 розробленого мобільного додатка можна керувати чотирма мікроконтролерними системами. Під керуванням однієї мікроконтролерної системи може знаходитися n'ять ділянок поливу. Керування з мобільного додатка п'ятьма і більше мікроконтролерними системами потребує додаткової оплати за обслуговування сервером.

Ключові слова: полив, трунт, сонячна енергетика, мікроконтролерна система, мобільний додаток.

Вступ. Площа зрошуваних земель в Україні становить 2,45 млн. га, 3 яких у зоні Степу знаходиться $80 \%$ земель. Більшість закритих зрошувальних систем виконана зі сталевих і азбестоцементних трубопроводів, загальна довжина яких відповідно становить 20 і 18 тис. км. Зрошення здійснюється найбільш поширеним способом поливу - дощуванням за допомогою широкозахватних дощувальних машин [1].

Зрошення або іригація - це комплекс господарських, інженерних, організаційних заходів, спрямованих на штучне зволоження грунту з метою створення сприятливих умов для росту п розвитку рослин.

Зрошення має забезпечувати оптимальний водний, поживний, повітряний, тепловий, сольовий і мікробіологічний режими грунтів. На території України зрошення використовується в Лісостепу тільки для найбільш вимог- ливих і економічно вигідних культур, у Степу - зрошення масштабне, а в Сухому Степу суцільне [2-3].

Режим зрошення - це правильно визначена й розподілена в часі (вегетаційному періоді) кількість зрошуваної води (число, норми й строки поливів), що забезпечує оптимальний для даної культури водний режим кореневмісного шару грунту для певних конкретних природних і агротехнічних умов.

Установлюється розрахунком відповідно до біологічних особливостей рослин, кліматичних, грунтових і гідрогеологічних умов зрошуваної ділянки, способу і техніки поливу, технології вирощування рослин тощо [3].

Режим зрошення буває двох типів:

- проектний (розрахунковий) - його розробляють при проектуванні зрошувальних систем. Від його показників залежать: розміри каналів, трубопроводів, параметри зрошуваль-

(C) О. Б. Півень, О. В. Бойко, 2019

DOI: $10.24025 / 2306-4412.4 .2019 .181610$ 
ної мережі, затрати на ії̈ будівництво та експлуатацію:

- експлуатаційний - його розробляють для існуючих меліоративних систем, для конкретних динамічних умов вегетаційного періоду, виходячи з погодних показників.

Для здійснення поливу сільськогосподарських земель, які знаходяться відносно далеко від ліній електропередач, доцільніше використовувати альтернативні джерела енергії.

Зазвичай устаткування для поливу сільськогосподарських полів знаходиться безпосередньо на полі. Для живлення насосних систем та управління поливом потрібна електроенергія, яку зазвичай потрібно передавати за допомогою лінії електропередач. Інколи прокладання ліній $є$ дуже затратним і неефективним, оскільки полив здійснюється лише в певний період року.

В остання десятиліття сонячна енергетика активно розвивається в світовій промисловості і побуті. Завдяки розвитку нових технологій і запровадженню субсидованих тарифів («зелених» тарифів) сонячні енергетичні системи і пристрої дають змогу здійснювати ефективний виробіток і економію електричної енергії через природні, практично невичерпні можливості світлового випромінювання Сонця із практично відсутнім впливом на екологічний стан довкілля [4-5]. Розробки і промислова продукція в цій галузі на сьогодні дуже активно розвиваються в таких країнах, як Нiмеччина, США, Великобританія, Японія, Корея, Китай, а також Україна [6].

В Україні найбільш ефективним періодом для експлуатації сонячних модулів $є$ термін від п'яти до семи місяців, що залежить від регіону 3 півночі на південь. Середньорічна кількість електроенергії, котру отримують регіони нашої країни від використання енергії сонця, становить приблизно 1200 кВт год. на квадратний метр [7].

Географічні умови розташування України дають можливість отримувати потрібну кількість сонячної енергії протягом усього року. Головним завданням при створенні систем автономного електроживлення на основі використання сонячної енергії є конфігурація системи залежно від потрібного режиму автономного електропостачання об'єкта.

Використання такого альтернативного джерела енергії, як Сонце дозволить зекономити велику кількість як традиційних джерел енергії, так і фінансових коштів [8].

(C) О. Б. Півень, О. В. Бойко, 2019

DOI: $10.24025 / 2306-4412.4 .2019 .181610$
Для налаштування роботи і моніторингу поливної системи необхідно створити відповідну систему та забезпечити зв'язок між користувачем та системою поливу. Тому створення ефективної і низьковитратної автономної системи поливу є актуальною задачею.

Узагальнений вигляд системи поливу зображено на рисунку 1 [9].

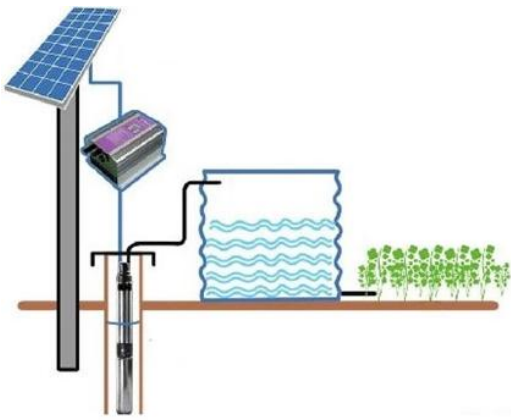

\section{Рисунок 1 - Узагальнений вигляд системи поливу}

Мета роботи. Розробити автоматизовану поливну систему, яка дасть змогу проводити моніторинг та управління поливною системою за допомогою мобільного телефону.

Задачі роботи. Пріоритетними задачами роботи є: пошук та порівняння з аналогічними системами, підбір комплектуючих системи, побудова схеми системи, написання програми для мікроконтролера, створення та налаштування зв'язку між поливною системою та мобільним телефоном, налаштування мобільного додатка.

Розв'язання поставленої задачі. Запропоновано автоматизовану систему поливу, яка має такі основні компоненти: сонячні панелі, частотний перетворювач, насос, водонапірна башта, електронний клапан для води, мікроконтролерна система i безпосередньо агрегати для поливу.

Bci компоненти цієї системи можуть бути варіативними і вибираються залежно від потрібних потужностей. Сама ж мікроконтролерна система буде універсальною для будьякого набору компонентів.

Мікроконтролерна система складається 3 таких компонентів: плата 3 мікроконтролером, датчики температури повітря та вологості грунту, годинник реального часу, датчики верхнього та нижнього рівня води, реле керування роботою водяного насоса та електромагнітним клапаном для води. 
Загальну схему мікроконтролерної системи зображено на рисунку 2.

Для реалізації цього проекту було вибрано мікроконтролерну систему на базі NodeMCU. Вибір цієї мікроконтролерної плати здійснений з урахуванням усіх необхідних потреб для проекту та гарним співвідношенням ціна-якість даного продукту. Головною перевагою цієї плати є вбудований WiFiмодуль, який не потрібно з'єднувати і налаштовувати для спільної роботи з іншими платами. Крім цього, плата поставляється $з$ прошивкою NodeMCU, що дозволяє програмувати іiі за допомогою програмного середовища Arduino IDE [10].

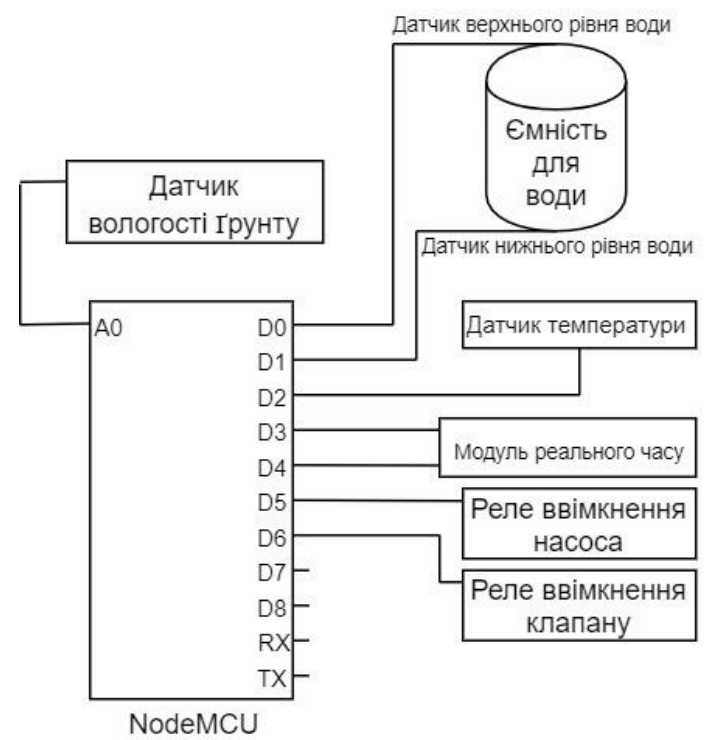

Рисунок 2 - Загальна схема мікроконтролерної системи

Система поливу використовує такі датчики: 1) датчики верхнього та нижнього рівнів води будуть передавати дані про стан наповнення ємності для води; 2) датчик модуля реального часу DS3231, оскільки він доволі простий та зручний у використанні [11]; 3) датчик температури DS18B20; 4) ємнісний датчик вологості грунту від DFRobot. Цей датчик підключається своїм інформаційним виходом до аналогового входу А0 на платі. В результаті отримуємо значення, яке потрібно перевести у відсотки. Для цього необхідно провести калібрування цього датчика. Спочатку потрібно заміряти показники датчика без контакту з водою, потім заміряти показники датчика, який знаходиться у воді [12]. Далі

(C) О. Б. Півень, О. В. Бойко, 2019

DOI: $10.24025 / 2306-4412.4 .2019 .181610$ виконується розрахунок вологості у відсотках за формулою

$$
w=\frac{w_{3 \mathrm{H}}-w_{\mathrm{cyx}}}{w_{\mathrm{Bод}}-w_{\mathrm{cyx}}} * 100,
$$

де $w_{3 н}$ - вимірюване значення датчика;

$w_{\text {cyx }}-$ значення датчика без контакту 3 водою;

$w_{\text {вод }}-$ значення датчика, який знаходиться у воді.

Також використовуються реле для ввімкнення насоса, розраховане на $380 \mathrm{~B}$, та реле для ввімкнення клапана поливної системи, розраховане на $12 \mathrm{~B}$.

Для забезпечення зв'язку між користувачем і системою управління та моніторингу поливу використовується мережа Інтернет. В цьому проекті використовується плата NodeMCU на базі чіпа ESP8266 (версія ESP12E), який є UART-WiFi модулем, що забезпечує зв'язок з мережею Інтернет за допомогою WiFi-роутера [13]. WiFi-роутер встановлюється на відстані 50-100 м від мікроконтролерної системи. Для зв'язку між мікроконтролерною системою та користувачем використовується спеціальний протокол MQTT. MQTT, або Message Queue Telemetry Transport - це легкий, компактний і відкритий протокол обміну даними, створений для передачі даних на віддалених локаціях, де потрібний невеликий розмір коду і $\epsilon$ обмеження по пропускній здатності каналу. Перераховані вище переваги дають можливість застосовувати MQTT у системах M2M (МашинноМашинна взаємодія) і IIoT (Промисловий Інтернет речей) [14].

Обмін повідомленнями в протоколі MQTT здійснюється між клієнтом (client), який може бути відправником або отримувачем (publisher / subscriber) повідомлень, і брокером (broker) повідомлень.

Відправник передає дані на MQTT брокер, вказуючи в повідомленні певну тему, топік (topic). Отримувачі можуть отримувати різні дані від багатьох відправників залежно від підписки на відповідні топіки.

Нами використано зручний сервіс www.cloudmqtt.com з безкоштовним тарифним планом (Cute Cat), який повністю покриває потреби для реалізації цього проекту [14-15].

Для отримання власного сервера потрібно пройти реєстрацію на сайті і отримати необхідні дані для доступу до сервера, а саме 
назву сервера, ім'я користувача, пароль користувача, номер порту та кількість клієнтів. Для налаштування клієнтів потрібно використати ці дані в коді програми (для мікроконтролерної системи).

Для можливості управління поливною системою та іiі моніторингу використовується мобільний додаток MQTT Dashboard, розроблений для операційної системи Android. При створенні нового клієнта в цьому додатку потрібно ввести необхідні дані для доступу до сервера та налаштувати відповідні топіки отримувача та відправника для цього клієнта. На рисунку 3 зображено загальний вигляд мобільного додатка MQTT Dashboard.

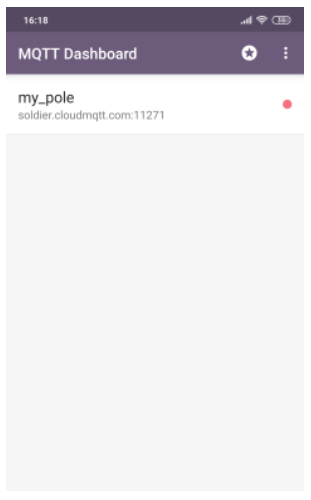

Рисунок 3 - Загальний вигляд мобільного додатка MQTT Dashboard

Для налаштування мікроконтролерної системи на роботу з відповідним MQTT сервером потрібно використати спеціальну бібліотеку «pubsubclient.h» і вказати необхідні дані для доступу до сервера та за допомогою команд 3 цієї бібліотеки налаштувати відповідні топіки отримувача та відправника для цього клієнта [15].

Алгоритм керування та моніторингу системи поливу. Спочатку відбувається підключення мікроконтролерної системи до бездротової мережі Wifi, параметри якої (назва i пароль) попередньо записані в коді програми. Потім здійснюється підключення мікроконтролерної системи до МQTT сервера, параметри якого (назва сервера і номер порту), а також логін і пароль користувача отримано на сервісі MQTT серверів після реєстрації.

Після вдалого підключення до МQTT сервера відбувається отримання показників датчиків.

Зчитування значення температури та виведення в градусах Цельсія відбувається за допомогою спеціальних бібліотек
«OneWire.h» та «DallasTemperature.h», які призначені для роботи з датчиком температури DS18B20. Це значення температури відправляється до MQTT сервера з відповідним тегом.

Зчитування значення вологості грунту та виведення у відсотках відбувається за допомогою спеціальної функції, яка перетворює значення на аналоговому вході на значення вологості у відсотках. Ця функція використовує значення, які потрібно вказати після проведення калібрування цього датчика, зокрема значення вологості грунту до MQTT сервера 3 відповідним тегом.

Далі відбувається зчитування стану датчиків верхнього та нижнього рівнів води, які встановлені в ємності для води зверху і знизу відповідно. В результаті ми отримуємо значення, на основі яких буде здійснюватися регуляція наповнення ємності для води та управління поливом. Якщо датчик рівня контактує з водою, то значення, яке отримає мікроконтролерна система, буде «0», в іншому разі значення буде протилежне. В результаті отриманих даних відправляється звіт про наповнення ємності для води до MQTT сервера з відповідним тегом.

Залежно від наповнення ємності для води, а також встановлених користувачем норми поливу та часу початку поливу відбувається початок поливу та розраховується час закінчення поливу.

Поточний час зчитується 3 модуля реального часу DS3231 за допомогою спеціальних бібліотек «Wire.h» та «RtcDS3231.h». За допомогою спеціальних функцій цих бібліотек здійснюється зчитування конкретних значень часу (години, хвилини, секунди) окремо.

Зчитування даних з MQTT сервера відбувається при надходженні відповідних даних від мобільного телефону до МQTT сервера 3 топіками, на які підписана мікроконтролерна система.

Залежно від назви топіка інформація, що надходить разом 3 назвою топіка, обробляється по-різному. Для топіка, який несе інформацію про норму поливу, відбувається запис у пам'ять системи значення норми поливу i за допомогою заздалегідь вказаного значення пропускної здатності електронного клапана для води здійснюється розрахунок тривалості поливу в хвилинах. Це значення використовується для розрахунку часу закінчення поливу. 
Для топіка, який несе інформацію про час початку поливу, відбувається запис у пам'ять системи значення годин та хвилин початку поливу, які використовуються для розрахунку часу кінця поливу.

Блок-схема алгоритму керування та моніторингу системи поливу зображена на рисунку 4.

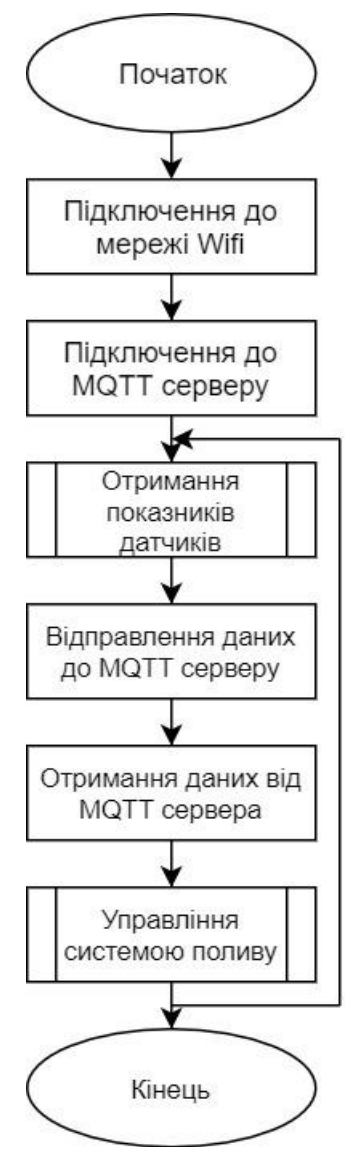

Рисунок 4 - Блок-схема алгоритму керування та моніторингу системи поливу

Інструкиія користувача. Після встановлення безкоштовного додатка MQTT Dashboard на власний телефон користувача 3 системою Android та його запуску потрібно додати нове з'єднання, вказавши дані сервера, порту, логін та пароль, які вказані на MQTT сервісі www.cloudmqtt.com. Заповнення необхідних даних зображено на рисунку 5.

Після цього можна додавати значення, які клієнт буде отримувати. При створенні нового значення потрібно вказати його назву, топік, розмірність тощо. Створення нового значення для отримання повідомлень зображено на рисунку 6.

(C) О. Б. Півень, О. В. Бойко, 2019

DOI: $10.24025 / 2306-4412.4 .2019 .181610$

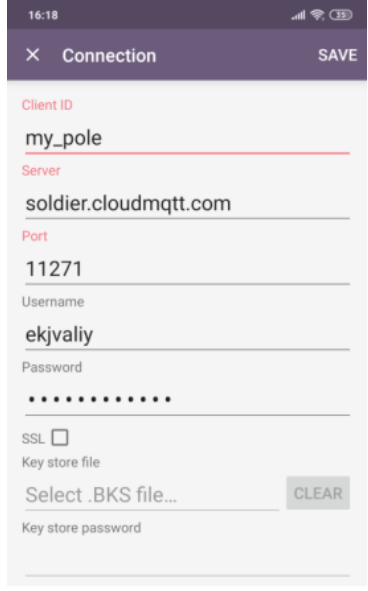

Рисунок 5 - Створення нового з'сднання в додатку MQTT Dashboard

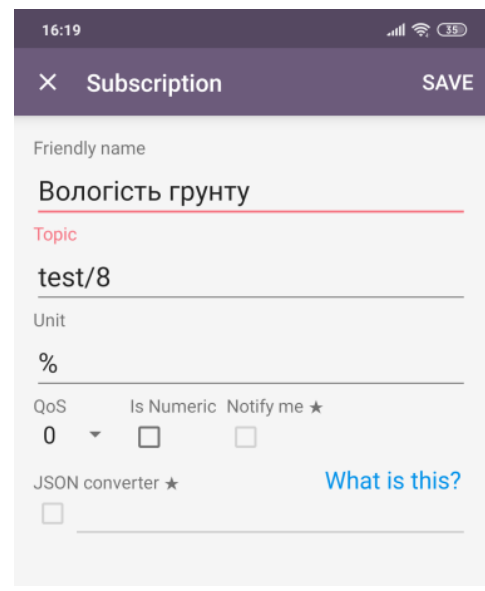

\section{Рисунок 6 - Створення нового значення для отримання повідомлень}

Також можна додавати значення, які клієнт має відправляти до сервера. При створенні нового значення потрібно обрати його тип. Доступні типи значень: текст (Text), кнопка (Button), перемикач (Switch), слайдер (SeekBar), комбінований список (ComboBox), палітра кольорів (ColorPicker), кнопкова панель (MultiButtons), годинник (TimePicker). Для кожного типу існують відповідні параметри. Створення нового значення для відправлення повідомлень до сервера на прикладі слайдера (SeekBar) зображено на рисунку 7.

Встановлення часу в значення годинника (TimePicker) зображено на рисунку 8.

Після додавання всіх необхідних значень для відправлення та прийому повідомлень від сервера формуються дві вкладки в додатку MQTT Dashboard: SUBCRIBE (значення для прийому повідомлень від сервера) та PUBLISH (значення для відправлення пові- 
домлень до сервера). Приклад вигляду вкладки SUBCRIBE зображено на рисунку 9.

Приклад вигляду вкладки PUBLISH зображено на рисунку 10.

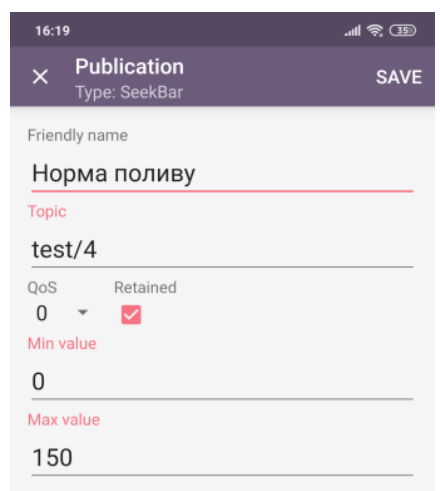

Рисунок 7 - Створення нового значення для відправлення повідомлень до сервера типу слайдер

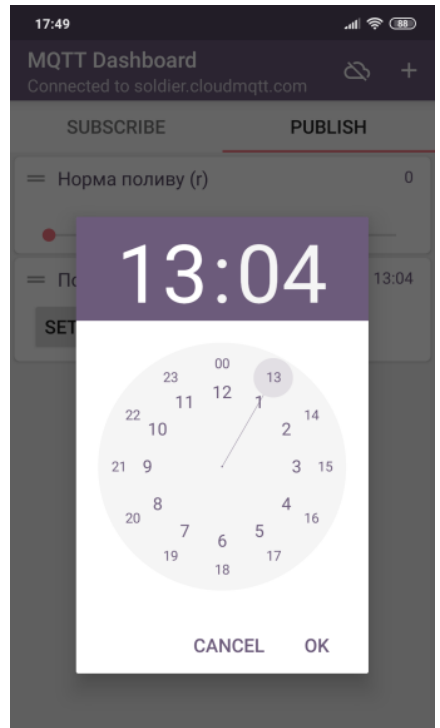

Рисунок 8 - Встановлення часу в значення годинника

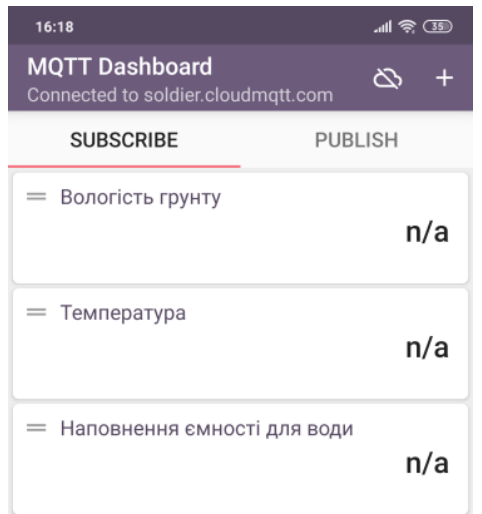

Рисунок 9 - Вигляд вкладки SUBCRIBE

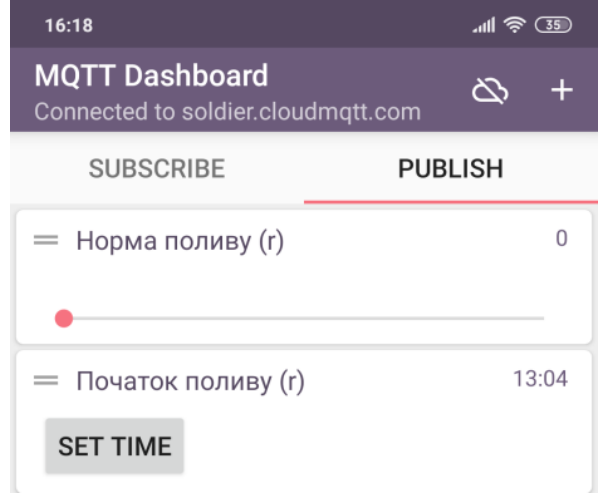

Рисунок 10 - Вигляд вкладки PUBLISH

3 мобільного додатка можна керувати чотирма мікроконтролерними системами. Одна мікроконтролерна система може керувати п'ятьма ділянками поливу. Керування п'ятьма і більше мікроконтролерними системами потребує додаткової оплати за обслуговування сервером.

В Україні існують аналогічні системи від компаній Аванте та Teplodom. В результаті оцінювання та порівняння цих двох систем було зроблено висновок, що вони в цілому досить схожі за своєю структурою та принципом роботи. Основні відмінності системи, яку було розроблено, від цих систем $\epsilon$ такими:

- відносно дешева мікроконтролерна система;

- відносно низька ціна на компоненти систем управління та моніторингу;

- можливість розділити основне поле на кілька частин та здійснювати полив цих частин окремо одна від одної;

- керування та моніторинг поливу здійснюються користувачем за допомогою додатка на мобільній операційній системі Android, який $є$ доступним, безкоштовним і простим у використанні.

Висновки. Розроблено автономну систему поливу багатьох ділянок землі під керуванням багатьох мікроконтролерних систем на базі NodeMCU. Керування автономною системою поливу здійснюється 3 мобільного додатка MQTT Dashboard для операційної системи Android. Запровадження автономної системи поливу дасть змогу збільшити врожайність сільськогосподарських культур на полях, які знаходяться на значній відстані від ліній електропередач, а також управляти поливом у режимі реального часу і здійснювати моніторинг та контроль за поливом. Також перевагою системи $є$ зниження іiї вартості. 


\section{Список літератури}

[1] В. А. Гурин, М. П. Степаненко, та М. Г. Степаненко, Технологія зрошування: навч. посіб. Рівне, Україна: НУВГП, 2013.

[2] Г. А. Мисик, та Б. Б. Куліковський, Основи меліораиії $і$ ландшафтознавства: посібник для студ. і викл. аграрних закл. вищ. освіти I-II рівня акредит. Київ, Україна: ІНКОС, 2005.

[3] Ю. В. Задорожній, Сільськогосподарська меліорація: курс лекцій. Миколаїв, Україна: МНАУ, 2014.

[4] Г. Г. Півняк, та Ф. П. Шкрабець, Альтернативна енергетика в Украӥні: монографія / М-во освіти і науки України, Держ. вищий навч. закл. «Нац. гірн. ун-т». Дніпропетровськ, Україна: НГУ, 2013. [Електронний ресурс]. Режим доступу: http://ir.nmu.org.ua/handle/123456789/3498

[5] В. И. Виссарионов, Солнечная энергети$\kappa a:$ учеб. пособие для вузов / под ред. В. И. Виссарионова. Москва, Россия: Изд. дом МЭИ, 2008.

[6] В. П. Кожем'яко, О. Г. Домбровський, та В. I. Маліновський, "Оптимізація проектів будівництва сонячних електростанцій iз врахуванням базових технікоекономічних показників", OEIET, vol. 30, № 2 , с. 66-81, 2016.

[7] П. П. Гаврилко, Р. С. Чорний, та Я. В. Шевчук, "Розвиток та впровадження сонячної енергетики в домогосподарствах України", Міжнародний науковий журнал, № 10 (20), 2 т., с. 66-71, 2016.

[8] О. О. Казіміров, К. В. Власов, А. І. Куртов, та А. І. Потіхенський, "Дослідження можливостей використання сонячної енергії для автономного живлення об'єкту", Системи обробки інформащіï, № 1 (147), c. 58-61, 2017.

[9] Солнечные батареи для орошения и капельного полива автономных и удаленных полей [Электронный ресурс]. Режим доступа: http://avante.com.ua/solnechnyebatarei-dlya-orosheniya-i-kapelnogo-polivaavtonomnykh-i-udalennykh-poley/

[10] В. А. Петин, Создание умного дома на базе Ардуино. Москва, Россия: ДМК Пресс, 2018.

[11] В. А. Петин, и А. А. Биняковский, Практическая энииклопедия Arduino. Москва, Россия: ДМК Пресс, 2016.
[12] Capacitive Soil Moisture Sensor SKU SEN0193 [Online]. Available: https://wiki.dfrobot.com/Capacitive_Soil_M oisture_Sensor_SKU_SEN0193

[13] Marco Schwartz. Internet of Things with ESP8266. Packt Publishing Ltd, 2016.

[14] Азы программирования ESP8266 [Электронный ресурс]. Режим доступа: http://wikihandbk.com/wiki/ESP8266:Моду ли/Азы_программирования_ESP8266

[15] Проекты умного дома и интернета вещей на основе Arduino и NodeMCU [Электронный pecypc]. Режим доступа: https://arduino-kit.ru/blogs/blog/ smart_home_projects

\section{References}

[1] V. A. Gurin, M. P. Stepanenko, and M. G. Stepanenko, Irrigation technology: textbook. Rivne, Ukraine: NUVGP, 2013 [in Ukrainian].

[2] G. A. Misik, and B. B. Kulikovsky, Fundamentals of land reclamation and landscape science: a guide for students and teachers of agricultural institutions of higher education of the I-II level of accreditation. Kyiv, Ukraine: INCOS, 2005 [in Ukrainian].

[3] Yu. V. Zadorozhny, Agricultural land reclamation: a lecture course. Mykolaiv, Ukraine: MNAU, 2014 [in Ukrainian].

[4] G. G. Pivnyak, and F. P. Shkrabets, Alternative energy in Ukraine: monograph / Ministry of Education and Science of Ukraine, State Higher Educational Institution "National Mining University". Dnipropetrovsk, Ukraine: NHU, 2013. [Online]. Available: http://ir.nmu.org.ua/ handle/123456789/3498

[5] V. I. Vissarionov, Solar energy: textbook for Universities, V. I. Vissarionov, Ed. Moscow, Russia: MEI Publ. House, 2008 [in Russian].

[6] V. P. Kozhemyako, O. G. Dombrovsky, and V. I. Malinovsky, "Optimization of solar power plant construction projects taking into account basic technical and economic indicators", OEIET, vol 30, no. 2, pp. 66-81, 2016 [in Ukrainian].

[7] P. P. Gavrilko, R. S. Chornyi, and Ya. V. Shevchuk, "Development and implementation of solar energy in Ukrainian households", Mizhnarodnyi naukovyi zhurnal, no. 10 (20), 2 vol., pp. 66-71, 2016 [in Ukrainian].

[8] O. O. Kazimirov， K. V. Vlasov， A. I. Kurtov, and A. I. Potikhenskyi, "Investigation of 
the possibilities of solar energy use for autonomous power supply of the object", Systemy obrobky informatsii, no. 1 (147), pp. 5861, 2017 [in Ukrainian].

[9] Solar batteries for irrigation and drip irrigation of autonomous and remote fields. [Online]. Available: http://avante.com.ua/ solnechnye-batarei-dlya-orosheniya-i-kapel nogo-poliva-avtonomnykh-i-udalennykhpoley/

[10] V. A. Petin, Creating a smart home based on Arduino. Moscow, Russia: DMK Press, 2018 [in Russian].

[11] V. A. Petin, and A. A. Binyakovsky, Arduino practical encyclopedia. Moscow, Russia: DMK Press, 2016 [in Russian].
[12] Capacitive Soil Moisture Sensor SKU SEN0193 [Online]. Available: https://wiki.dfrobot.com/Capacitive_Soil_M oisture_Sensor_SKU_SEN0193

[13] Marco Schwartz. Internet of Things with ESP8266. Packt Publishing Ltd, 2016.

[14] The basics of ESP8266 programming. [Online]. Available: http://wikihandbk.com/ wiki/ESP8266:Модули/Азы_программирова ния_ESP8266

[15] Smart home and internet of things projects based on Arduino and NodeMCU. [Online]. Available: https://arduino-kit.ru/blogs/blog/ smart_home_projects

O. B. Piven, Ph. D., professor, e-mail: pivolegbor@gmail.com

O. V. Boyko, undergraduate e-mail: boyko7894@gmail.com

Cherkasy State Technological University

Shevchenko blvd, 460, Cherkasy, 18006, Ukraine

\section{MICROCONTROLLER CONTROL SYSTEM OF LAND PLOTS IRRIGATION WITH DATA EXCHANGE}

A microcontroller system running the mobile application for the Android operating system, which allows monitoring and control of the land plots irrigation system, is offered. An autonomous irrigation system for many plots of land under the control of many microcontroller systems based on NodeMCU has been developed. In the context of global warming, the development of efficient and relatively inexpensive systems of automated irrigation of land for the full cultivation of different crops is becoming relevant. Automatic irrigation of crops allows to increase their productivity considerably at rather small expenses. The developed system of automated irrigation does not require significant investments and has the optimum price / quality ratio, is easy to use and has technical capabilities to increase the number of land plots for automated irrigation. The automated irrigation system includes: solar panels, frequency converter, pump, water tank, electronic water valve, microcontroller system and irrigation units. The microcontroller system consists of the following components: microcontroller board, air temperature and humidity sensors, real time clock, upper and lower water level sensors, control relay for water pump and solenoid valve for water. Special MQTT protocol is used to communicate with the microcontroller system and the user. This protocol is commonly used in M2M (Machine-Machine Interaction) and IIoT (Industrial Internet of Things) systems. The MQTT Dashboard mobile application developed for the Android operating system is used to control and monitor the irrigation system. With the developed mobile application, it is possible to control four microcontroller systems. Up to five irrigation sections can be controlled by one microcontroller system. The control of five or more microcontroller systems from a mobile application requires an additional fee for server maintenance.

Keywords: irrigation, soil, solar power, microcontroller system, mobile application.

Стаття надійшла 25.10.2019

Прийнято 11.11.2019

(C) О. Б. Півень, О. В. Бойко, 2019

DOI: $10.24025 / 2306-4412.4 .2019 .181610$ 